
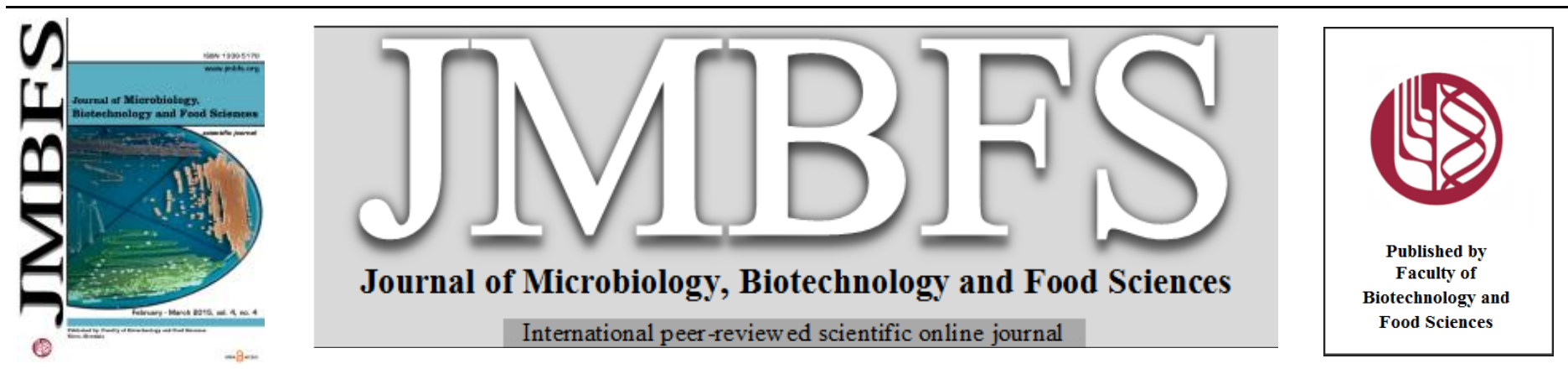

\title{
EXPLORATION OF ACTINOMYCETES ENDOPHYTICALLY ASSOCIATED WITH PIPER NIGRUM FOR POTENTIAL BIOACTIVITY
}

\author{
Jasim B., Soumya Rajappan, Jyothis Mathew and Radhakrishnan E. K.
}

Address(es): Dr. Radhakrishnan E.K

School of Biosciences, Mahatma Gandhi University, Priyadharshini Hills PO, Kottayam Dist, Kerala, India, Pin 686560.

*Corresponding author: radhakrishnanek@mgu.ac.in

doi: 10.15414/jmbfs.2015.4.4.282-286

\section{ARTICLE INFO}

Received 3. 12. 2013

Revised 14. 10. 2014

Accepted 16. 11. 2014

Published 1.2. 2015

Regular article

open $\partial$ access

\begin{abstract}
Piper nigrum is well known for its metabolite richness. So endophytic microorganisms that reside within such environments can be expected to have promising biosynthetic potential. The current study identified three endophytic actinomycetes with broad bioactivity which can have applications in natural product related pharmacological research. The Verrucosispora sp identified in the study was found to have promising anticancer and antimicrobial activities and Streptomyces sp. was found to have antioxidant activity. The results obtained are supported by many previous reports and this suggests the isolates obtained in the study to have the possible presence of potential known or novel compounds with broad spectrum of activity.
\end{abstract}

Keywords: Endophytic actinomycetes, MTT assay, DPPH assay, 16S rDNA sequencing, Streptomyces sp., Verrucosispora sp.

\section{INTRODUCTION}

Black pepper (Piper nigrum), which belongs to the family Piperaceae is an ingredient of almost all important traditional medicines and is one of the ancient and important spice crops of India. The broad bioactivity of the plant is due to the presence of diverse metabolites including piperine, which is the principle ingredient of pepper (Vijayakumar et al., 2004). There are many other terpenoids like pinene, sabinene, limonene, caryophyllene and linalool that contributes to the medicinal properties of the plant. These compounds can have varying pharmacological effects including anti-fertility (Vladimirov et al., 1991), anti-inflammatory (Lee et al., 1984), bioavailability of drugs (Allameh et al., 1992; Khajuria et al., 2002), stimulation of release of epinephrine (Kawada et al., 1988) and elevation of levels of circulating thyroid hormones (Tripathi \& Tripathi, 1989). Because of the presence of these kinds of diverse metabolites, the microbes that live inside the plant as endophytes can also expected to have same or similar or novel compounds with superior biological effects.

Endophytic microorganisms reside within the internal tissue of plants for whole or part of their life time without causing immediately overt negative effects (Long et al., 2008). As actinobacteria are known to have the capability to produce diverse range of secondary metabolites with antibiotic, antitumor and immunosuppressive properties, exploration of those actinomycetes of endophytic origin can have much applications (Locci, 1989; Berdy, 2005). There are many reports on the production of novel bioactive compounds by endophytic actinobacteria isolated from a wide range of plants like tomato, banana, wheat, and maize with promising antipathogenic activities (Coombs \& Franco, 2003; Castillo et al., 2007). However the actinomycetes which are endophytically associated with metabolically diverse plants like $P$. nigrum is least studied and can be a better source for metabolites with diverse biological activities with promising applications in drug development.

In the present study focus was made to isolate and identify endophytically associated actinomycetes from $P$. nigrum which resulted in the isolation of three distinct isolates. The isolates were identified by $16 \mathrm{~S}$ rDNA sequence based method as PnA 1 (Verrucosispora sp.), PnA 2 (Streptomyces sp.) and PnA 3 (Streptomyces clavatus). These isolates were screened for the antibacterial, antioxidant and anticancer activities which showed its promising bioactivity. The diverse activity shown by the isolates can be due to the presence of various compound(s) with potential bioactivity.

\section{MATERIALS AND METHODS}

\section{Isolation of endophytic actinomycetes from Piper nigrum}

Stem pieces of Piper nigrum plants collected from Navajyothi Sree Karunakara Guru Research Centre for Ayurveda and Siddha, Uzhavoor, Kottayam were used as source material for the isolation of endophytic actinomycetes. The collected material was washed and cut into segments of $2-3 \mathrm{~cm}$ long and the surface sterilization was conducted as per the methods reported by Jasim $\boldsymbol{e t}$ al. (2013). The plant material was surface sterilized with $2 \%$ sodium hypochlorite for 10 min. and washed with sterilized distilled water. Further, they were treated with $70 \%$ alcohol for one min. followed by wash with sterilized distilled water. For sterility check, $0.1 \mathrm{ml}$ aliquot from the final wash was inoculated to ISP 3, Glycerol Arginine agar (ISP 5), ISP 6 and Low Nutrient Mineral Salt (LNMS) agar amended with $50 \mu \mathrm{g} / \mathrm{mL}$ nystatin and nalidixic acid to prevent fungal and bacterial growth. The surface sterilized stem pieces were placed on the above media with three replicates. The inoculated plates were incubated at room temperature for 5 to 7 days. The individual colonies from each plate was selected and sub-cultured further on respective media used for isolation. Those batches of experiments where the bacterial growth, if any present, in the control plate were completely discarded. In such cases the entire experiment was repeated by modifying the sterilization procedures. The colonies with different morphological characters were selected, purified and used for further studies.

\section{Identification and characterization of the isolates}

The isolates were identified and characterized by using 16S rDNA sequencing. For this, the DNA was isolated from all the strains. For the DNA isolation, the isolates were inoculated separately into $20 \mathrm{~mL}$ of Tryptone Yeast Extract Broth (g.L $\mathrm{L}^{-1}$ - Casein enzymatic hydrolysate 6g, Yeast Extract $3 \mathrm{~g}, \mathrm{pH} 7.2 \pm 0.2$ ) and incubated for 7 days in a shaking incubator. After incubation the biomass of the isolates were harvested by centrifuging the culture at $8000 \mathrm{rpm}$ for $10 \mathrm{~min}$ at $4^{\circ} \mathrm{C}$ and the genomic DNA was isolated using genomic DNA isolation kit (Chromous Biotech). The presence of DNA in the eluted sample was confirmed by using $0.8 \%(\mathrm{w} / \mathrm{v})$ agarose gel and it was used as the template for amplifying the $16 \mathrm{~S}$ rDNA. The primers used for the PCR amplification were $27 \mathrm{~F}\left(5^{\prime}-\mathrm{AgA}\right.$ gTT TgA TCM Tgg CTC Ag-3') and 1492r (5'-TAC ggY TAC CTT gTT ACg ACT T-3') (Coombs \& Franco, 2003). PCR was carried out in a $50 \mu \mathrm{L}$ reaction volume containing 50ng of genomic DNA, 20picomoles of each primer (both forward and reverse), 1.25 units of Taq DNA polymerase (Bangalore Genei), $200 \mu \mathrm{M}$ of each dNTPs and 1X PCR buffer. PCR was carried out for 35 cycles in a Mycycler ${ }^{\mathrm{TM}}$ (Bio-Rad, USA) with the initial denaturation at $94^{\circ} \mathrm{C}$ for $5 \mathrm{~min}$, cyclic 
denaturation at $94^{\circ} \mathrm{C}$ for $30 \mathrm{sec}$, annealing at $58^{\circ} \mathrm{C}$ for $30 \mathrm{sec}$ and extension at $72^{\circ} \mathrm{C}$ for $2 \mathrm{~min}$ with a final extension of $7 \mathrm{~min}$ at $72^{\circ} \mathrm{C}$. The amplified PCR product was visualized by electrophoresis in $1.2 \%$ (wt/vol) agarose gel incorporated with $2 \mu 1$ of ethidium bromide $(10 \mathrm{mg} / \mathrm{ml})$ for confirmation of amplification. The PCR product was then gel purified and was used for sequencing. Sequencing PCR was carried out using the Big Dye Terminator Sequence Reaction Ready Mix (Applied Biosystem). The sequencing product was purified and sequence run was carried out in the DNA sequencer ABI 310 Genetic Analyzer. The sequence data obtained was further analyzed by BLAST (Zhang $\boldsymbol{e t}$ al., 2000). For the phylogenetic analysis, the related sequences were retrieved from NCBI. The selected sequences were first aligned with ClustalW program. The aligned data was boot strap replicates (Tamura et al., 2011).

\section{Fermentation and extraction of the crude metabolites}

The isolates were grown in Tryptone yeast extract broth for 7 days in a shaking incubator. After incubation, the culture supernatant was obtained by centrifugation at $10000 \mathrm{rpm}$ for 10 minutes. The fermented broth was then acidified to $\mathrm{pH} 2$ with $1 \mathrm{~N} \mathrm{HCl}$. The acidified broth was then extracted twice with ethyl acetate and the solvent phase was collected. The solvent phase was then subjected to evaporation at $45^{\circ} \mathrm{C}$ under vacuum in a rotary evaporator. The residual powder was reconstituted in $1.5 \mathrm{~mL}$ methanol. Uninoculated broth extracted and evaporated and resuspended in methanol served as the control.

\section{Screening the extract for antimicrobial activity}

For the screening of antimicrobial activity, agar well diffusion method was used A lawn culture of pathogenic bacteria (Bacillus subtilis (MTCC121), Salmonella typhi (MTCC734), Salmonella paratyphi (MTCC735), Staphylococcus aureus (MTCC96) and Vibrio cholera (MTCC3906) was made by using the inocula prepared by adjusting the turbidity of the suspension to match the $0.5 \mathrm{McFarland}$ standard on Muller Hinton agar using a sterile cotton swab. After swabbing, wells were punched on the plates and $60 \mu \mathrm{L}$ of the corresponding extracts were added. The plates were incubated overnight at $37^{\circ} \mathrm{C}$ and observed for zone of inhibition. The zone of inhibition was measured using a zone measuring scale.

\section{Screening the extracts for antioxidant property}

The antioxidant activity of the extracts was assessed on the basis of the radica scavenging effect by using 1,1-diphenyl-2-picrylhydrazyl (DPPH) by modified method. The diluted working solutions of the test extracts were prepared in methanol. Ascorbic acid $\left(5 \mathrm{mg} \cdot \mathrm{mL}^{-1}\right)$ prepared in methanol was used as standard $150 \mu \mathrm{L}$ of $\mathrm{DPPH}(0.002 \%)$ prepared in methanol was mixed with varying concentration $(5-50 \mu \mathrm{L})$ of samples and standard was made up to $50 \mu \mathrm{L}$ using methanol. These solution mixtures were kept in dark for $30 \mathrm{~min}$ and optical density was measured at $517 \mathrm{~nm}$ using BIORAD micro-titre plate reader Methanol with DPPH solution $(0.002 \%)$ was used as blank. The optical density was recorded and \% inhibition was calculated by using the following formula Graph was plotted using the \% inhibition values against the concentration and $50 \%$ inhibition $\left(\mathrm{IC}_{50}\right)$ for each samples were calculated.

$$
\% \text { inhibition }=\frac{\text { Absorbance of control }- \text { Absorbance of Test }}{\text { Absorbance of control }} \times 100
$$

Screening the extracts for anticancer property.
HCT-15 colon carcinoma cell lines purchased from NCCS Pune maintained in Dulbecco's modified eagle's media (DMEM) and grown to confluency at $37^{\circ} \mathrm{C}$ and $5 \% \mathrm{CO}_{2}$ was used for screening the anticancer property of the extracts. The cells were trypsinized by using $500 \mu \mathrm{L}$ of $0.025 \%$ (w/v) Trypsin in PBS for 2 minutes and aseptically transferred to a microtitre plate and incubated. After attaining $80 \%$ cell confluency, $5 \mu \mathrm{L}$ of sample extracts were added to corresponding wells and incubated for 24 hours. The anti-proliferative effect of crude extracts was determined by MTT cell viability assay as described by Mosmann (1983). MTT (3-(4,5-dimethylthiazol-2-yl)-2,5-diphenyl tetrazolium bromide) was dissolved in phosphate buffered saline at $5 \mathrm{mg} / \mathrm{mL}$ and was sterilized using filtration. After incubation the plates were washed with PBS and $200 \mu \mathrm{L}$ of sterile MTT reagent was added to the wells and was incubated at $37^{\circ} \mathrm{C}$ for $4 \mathrm{~h}$ in a $\mathrm{CO}_{2}$ incubator. After incubation the optical density was measured at $540 \mathrm{~nm}$ for the formation of formazan during cell respiration using a microtitre plate reader.

$$
\% \text { viability }=\frac{\text { Absorbance of test }}{\text { Absorbance of blank }} \times 100
$$

\section{Statistical analysis}

The results were analysed using statistical software Origin 7 (Northampton, MA, USA) by oneway ANOVA. Post hoc multiple comparison test was used to determine the significant difference among the experiments. The data is presented as mean $\pm \mathrm{SD}$ from three different experiments. $\mathrm{p}<0.05$ was considered significant (Rihua et al., 2011).

\section{RESULTS}

\section{Isolation of endophytic actinomycetes}

Seven days incubation of surface sterilized stem pieces of $P$. nigrum resulted in the isolation of three morphologically distinct endophytic actinomycetes on various media. The isolates thus obtained were designated as PnA 1, PnA2 and PnA 3. Due to the absence of microbial growth on the representive control plate which contained the final wash of the surface sterilized material, the isolates obtained can be confirmed as endophytes. The obtained isolates were purified and subcultured in ISP 5 (Glycerol Asparagine Agar Base) medium for further analysis.

\section{Identification of the endophytic actinomycetes}

The PCR amplification of the $16 \mathrm{~S}$ rDNA of the isolated endophytic actinomycetes was confirmed by agarose gel electrophoresis in which formation of band of approximately $1500 \mathrm{bp}$ was observed. The 16S rDNA sequences obtained by the sequencing were submitted to NCBI under the accession number mentioned in Table 1. The obtained sequences were subjected to similarity analysis using NCBI BLAST which showed the isolate PnA 1 and PnA 2 to have $100 \%$ identity to Verrucosispora sp. (FJ999581) and Streptomyces sp. (HQ992748) respectively. However the isolate PnA 3 showed 99\% similarity towards Streptomyces carpaticus (HQ711933). The phylogenetic analysis which was conducted using the sequence obtained along with the sequence retrieved from NCBI confirmed the BLAST result by distinct clustering of the isolates (Figure 1).

Table 1 Identification of the endophytic actinobacterial isolates from Piper nigrum by $16 \mathrm{~S}$ rDNA sequence similarity method.

\begin{tabular}{lccccc}
\hline $\begin{array}{l}\text { Isolate } \\
\text { name }\end{array}$ & Media used & $\begin{array}{c}\text { Accession } \\
\text { number }\end{array}$ & $\begin{array}{c}\text { Similarity } \\
(\boldsymbol{\%})\end{array}$ & $\begin{array}{c}\text { Closest match with accession } \\
\text { number }\end{array}$ & Identified as \\
\hline \hline PnA 1 & LNMS & KC193251 & 100 & Verrucosispora sp. (FJ999581) & Verrucosispora sp. \\
\hline PnA 2 & ISP3 & KC193252 & 100 & Streptomyces sp. (HQ992748) & Streptomyces sp. \\
\hline PnA 3 & ISP6 & KC193253 & 99 & Streptomyces carpaticus (HQ711933) & Streptomyces carpaticus \\
\hline \hline
\end{tabular}

\section{Screening the extract for antimicrobial activity}

The fermented broth of the isolates and the control were extracted, dried and reconstituted in methanol and was used for screening its antimicrobial activity. From the results, Verrucosispora sp. was found to inhibit the growth of all the five pathogenic bacteria with a zone diameter of 15 to $20 \mathrm{~mm}$. At the same time, Streptomyces sp. was found to have inhibitory effects on four pathogens namely Bacillus subtilis, Salmonella typhi, Staphylococcus aureus and Vibrio cholerae. However Streptomyces carpaticus had an inhibition against Bacillus subtilis, Staphylococcus aureus and Vibrio cholerae only (Table 2).
Table 2 Antimicrobial activity of actinomycetes endophytically associated with P. nigrum

\begin{tabular}{lllllll}
\hline \hline \multirow{2}{*}{ Isolates } & \multicolumn{6}{l}{ Test organism (inhibition zone in mm) } \\
\cline { 2 - 7 } & S. aureus & V. cholerae & B. subtilis & S. para typhi & S. typhi \\
\hline \hline PnA 1 & 17 & 20 & 19 & 15 & 21 \\
\hline PnA 2 & 13 & 15 & 16 & 0 & 14 \\
\hline PnA 3 & 12 & 16 & 12 & 0 & 0 \\
\hline \hline
\end{tabular}




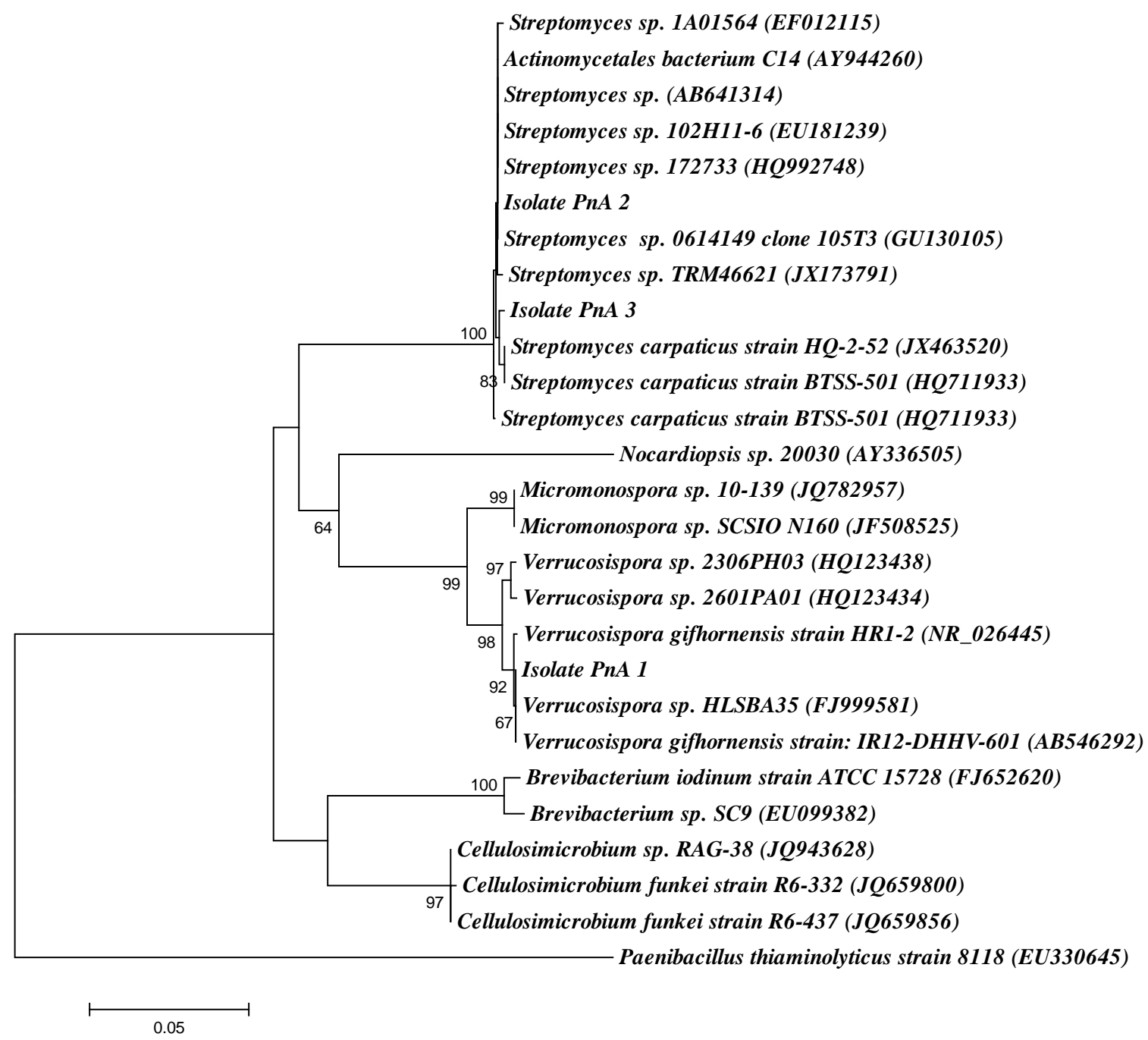

Figure 1 The phylogenetic analysis of partial 16S rDNA sequences of the endophytic actinomycetes isolated from Piper nigrum along with sequences from NCBI using MEGA 5 with neighbor joining method using 1000 bootstrap replicates.

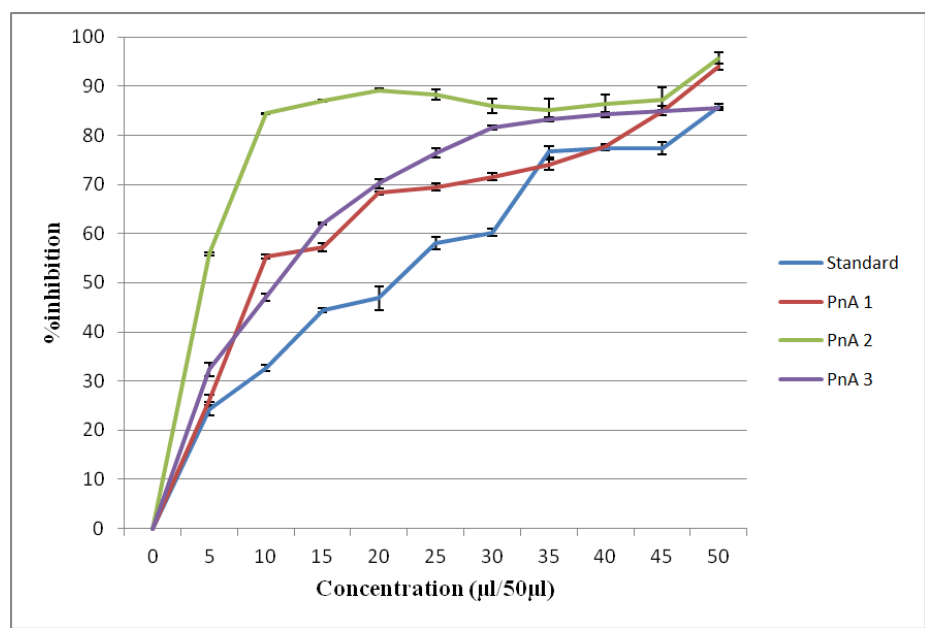

Figure 2 Graph showing the average \% inhibition when analyzed for antioxidant activity of the crude methanolic extracts of the endophytic actinomycetes from Piper nigrum and standard at different concentration. Data presented as mean \pm $\mathrm{SD}$ of three separate experiments.

Screening the extracts for antioxidant property

The screening of antioxidant activity was performed by DPPH assay. The \% inhibition of the samples was calculated based on the formula absorbance obtained from the blank and the test. When this was plotted on a graph, the isolate PnA 2 showed maximum activity by getting the highest percentage of about $85 \%$ activity at around $10 \mu \mathrm{L}$ of the crude methanolic extract. In the case of extracts of other isolates (PnA 1 and PnA 3) and standard (5mg/mL ascorbic acid) similar percentage of inhibition was observed at $50 \mu \mathrm{L}$ sample (Figure 2). The results of
$\mathrm{IC}_{50}$ clearly indicate the antioxidant capacity of isolate PnA 2 which needed only a very low concentration to attain the $50 \%$ inhibition which is very interesting (Figure 3). The mean and standard deviation of the 50\% inhibition was summarized as table 3 .

Table 3 Antioxidant activity of the endophytic actinomycetes isolated from Piper nigrum. Data is presented as mean $\pm \mathrm{SD}$ of three separate experiments.

Sample Name of sample Antioxidant activity

\begin{tabular}{llc}
\hline \hline Standard & Ascorbic acid & $21.3 \pm 1.5$ \\
\hline PnA 1 & Verrucosispora sp. & $9.5 \pm 0.5$ \\
\hline PnA 2 & Streptomyces sp. & $5.2 \pm 0.2$ \\
\hline PnA 3 & Streptomyces carpaticus & $10.4 \pm 0.4$ \\
\hline \hline
\end{tabular}




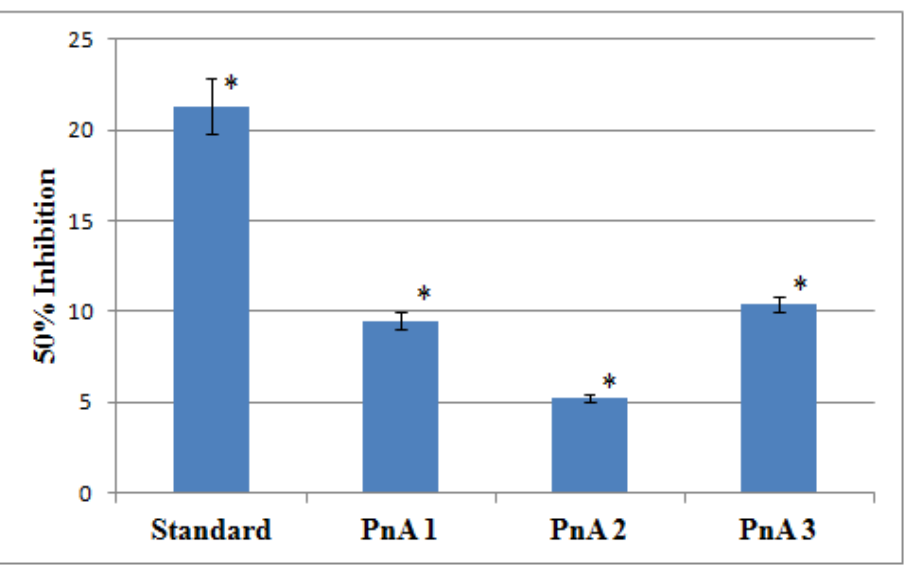

Figure 3 Graph showing the 50\% inhibition when analyzed for antioxidant activity of the crude methanolic extracts of the endophytic actinomycetes from Piper nigrum when compared to the standard. Data represented as mean \pm SD of three separate experiments. $* \mathrm{p}<0.05$.

\section{Screening of the extracts for anticancer property}

The screening of the antiproliferative activity of the extracts was performed on HCT-15 colon carcinoma cell lines by MTT assay. All the three isolates obtained were screened and all had promising antiproliferative activity. Among the isolates, extracts from PnA 1 showed the higher activity by getting the lowest $\%$ viability of about $48 \%$ when the cells were treated with $5 \mu \mathrm{L}$ of the methanolic extract. The \% viability obtained is summarized as Table $\mathbf{4}$ and based on the graph it is clear that the extracts from all the isolates showed significant antiproliferative effect when compared to the control (extract from uninoculated ISP 1 broth) (Figure 4). The obtained results were checked for its statistical significance using ANOVA and confirmed that $\mathrm{p}<0.05$.

Table 4 Anticancer activity of the endophytic actinomycetes isolated from Piper nigrum. Data is presented as mean $\pm \mathrm{SD}$ of three separate experiments.

\section{Sample Name of sample Anticancer activity (\% Viability)}

\begin{tabular}{llc}
\hline \hline Control & Uninoculated ISP 1 medium & $98.36 \pm 1.64$ \\
\hline PnA 1 & Verrucosispora sp. & $48.36 \pm 2.13$ \\
\hline PnA 2 & Streptomyces sp. & $50 \pm 2.17$ \\
\hline PnA 3 & Streptomyces carpaticus & $55.46 \pm 2.50$ \\
\hline \hline
\end{tabular}

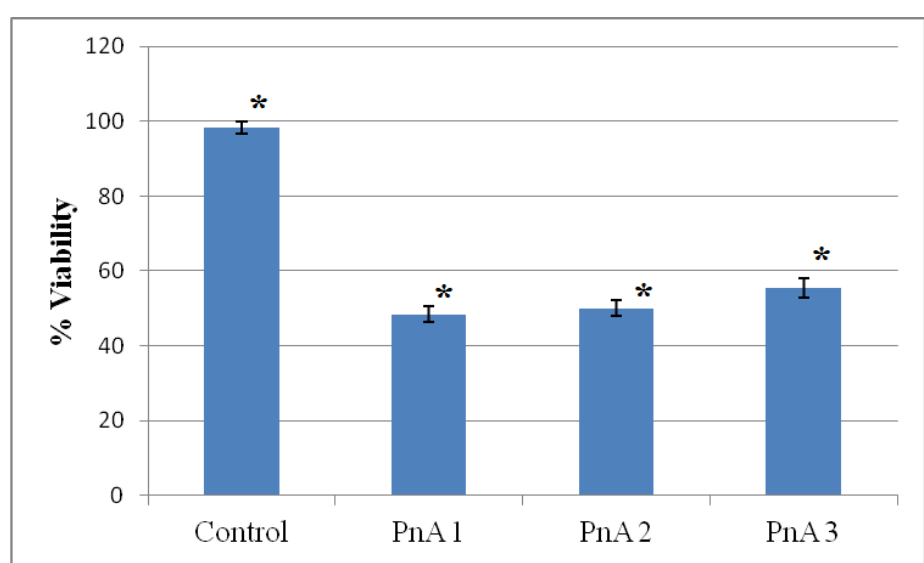

Figure 4 Graph showing the $\%$ viability of the cancer cells when analysed for anticancer activity of the crude methanolic extracts of the endophytic actinomycetes from Piper nigrum when compared to the standard. Data represented as mean \pm SD of three separate experiments. $* \mathrm{p}<0.05$.

\section{DISCUSSION}

By occupying the unique chemical environment of host plants, the endophytic actinomycetes can expect to have much biosynthetic potential. In the presen study, three actinomycetes were isolated and identified from surface sterilized stem portion of Piper nigrum. The endophytic actinomycetes were identified by PCR based method using 16S rDNA sequencing. The molecular identification of microorganisms by using $16 \mathrm{~S}$ rDNA sequence based method is considered to be the most efficient and rapid method (Clarridge, 2004). The sequence similarity analysis using NCBI BLAST identified the isolates as Verrucosispora sp. (PnA 1), Streptomyces sp. ( $\mathrm{PnA} 2$ ) and Streptomyces carpaticus ( $\mathrm{PnA} 3)$. Th phylogenetic analysis conducted using MEGA5 also supported the result of the similarity analysis by forming distinct clustering of the isolates with related species (Figure 1). Eventhough only three isolates were obtained in the current study, they were found to have promising potential based on the available information from other members of the genus reported from other sources. The reports of Houbo et al. (2012) shows the isolation of novel strains of Verrucosispora sp endophytically associated with the marine plant Thalassia hemprichii (seagrass). Similarly many reports show the presence of novel biologically active Streptomycetes sp. associated with wide range of plants (Castillo et al., 2007). Even some of them are known to have antiphytopathogenic properties as in the case of endophytic Streptomyces sp. with activity against Colletotrichum musae and Fusarium oxysporum (Taechowisan et al., 2005). From these reports it can also be confirmed that the microorganisms of the same genus as obtained in the study are present as endophytic inhabitant of a wide range of plants, also previous reports of the same from Piper nigrum is very limited.

All the three organisms obtained were found to have potent antibacterial effect. The isolate PnA 1 which belongs to Verrucosispora sp. were found to be active against all the tested pathogens. Streptomyces sp. was found to inhibit Bacillus subtilis, Staphylococcus aureus, Salmonella paratyphi and Vibrio cholerae but Streptomyces carpaticus was inhibitory towards Bacillus subtilis, Staphylococcus aureus and Vibrio cholera only.

The genus Verrucosispora has gained much importance because of its ability to produce antibiotic abyssomicin which could inhibit p-aminobenzoic acid biosynthesis and also aminofuran proximicins (Fiedler $\boldsymbol{e t}$ al., 2008; Riedlinger $\boldsymbol{e t}$ al., 2004). There are also reports on Verrucosispora sp. from marine sources which has been explored for its ability to synthesise bioactive metabolites. But reports on exploration of endophytically associated Verrucosispora sp. is very limited. As the endophytic isolates live in a specific chemical environment, it may favour the isolates to develop biosynthetic machinery for the synthesis of still more interesting compounds possibly in a strain specific manner.

The studies of Ghadin et al. (2008) explain the high inhibitory effect of the extracts from Streptomycetes sp. towards both gram positive and negative organisms when compared with standard antibiotics that are in clinical practice. Also there are recent reports suggesting the synthesis of new antibiotics like alnumycin, munumbicins $\mathrm{A}$ to $\mathrm{D}$, and coronamycins from endophytic Streptomyces sp. (Qin et al., 2009). Some strains of Streptomyces sp. even have the ability to act on Trypanosoma sp., a protozoan that causes the sleeping sickness (Zin et al., 2011). These reports can be intimation for the occurrence of still novel compounds in various unexplored endophytic Streptomyces sp. which may have the potential to replace even the drugs in practice.

The results of the antioxidant activity was highly interesting as the three isolates were having a distinct $\%$ inhibition pattern. From the \% inhibition patterns it was clear that the isolate PnA 2 has the maximum activity by attaining $85 \%$ activity at around $10 \mu \mathrm{L}$ of the crude methanolic extract. Eventhough the extracts of other isolates (PnA 1 and PnA 3) and standard (5mg. $\mathrm{mL}^{-1}$ ascorbic acid) showed antioxidant property, they required a higher concentration of around $50 \mu \mathrm{L}$ for attaining a similar percentage of inhibition. This result was also supported by the $\mathrm{IC}_{50}$ result as the isolate PnA 2 showed a low concentration to attain the 50\% inhibition. Free radicals and oxidants are toxic to the body as it has implications in the development of many human diseases including arthritis, inflammatory diseases, kidney diseases, cataracts, inflammatory bowel disease, colitis, lung dysfunction; pancreatitis; drug reactions, skin lesions, and aging (Thenmozhi \& Kannabiran, 2012). Thus the identification of compounds having antioxidant properties are very important. A melanin pigment isolated from Streptomyces sp. with an excellent antioxidant property was reported by Silambarasan $\boldsymbol{e t}$ al. (2012). Many of the previous studies demonstrates the ability of Streptomyces to synthesise a wide range of compounds with antioxidant activity like isoflavonoids (Komiyama et al., 1989), diphenazithionin (Hosoya et al., 1996), dihydroherbimycin A (Chang \& Kim, 2007), poly-saccharide (He et al., 2008) and protocatechualdehyde (Kim et al., 2008). These reports clearly supports the results obtained in the current study and provides a background indication that the isolates obtained in the study can be expected to have known or novel bioactive compounds with wide pharmacological applications.

When the Colon carcinoma cell line HCT-15 was treated with the extracts of the isolates, PnA 1 showed the higher activity by reducing the viability of the cancer cells to about $48 \%$ even when they were treated with $5 \mu \mathrm{L}$ of the methanolic extract. The extracts of the other two isolates also showed inhibitory property to the cells, but with a lower activity. Strains of Verrucosispora are the focus area for researchers as they are the source for a wide array of novel bioactive compounds. Reports suggest that Proximicins, a compound produced by a marine Verrucosispora sp. can have strong cytostatic effect towards various human tumor cell lines (Fiedler et al., 2008). Also these organisms have gained much importance after the demonstration of its ability to synthesise diterpene gifhornenolones A and B by specific Verrucosispora sp. (Shirai et al., 2010). The whole genome sequence of marine Verrucosispora sp. suggests the presence of around 23 biosynthetic gene clusters that encodes the production of known and predicted secondary metabolites (Roh et al., 2011). This indicates that the isolate obtained in the study can be expected to have the ability to produce more diverse 
metabolites which can be used as novel candidates for development of drugs with potential applications.

The assay on antiproliferative effects of Streptopyrrolidine and Daryamides isolated from marine Streptomyces on human colon carcinoma cell line HCT-116 confirms potent activity of the isolates. The assessment of cytotoxicity is very important as it is a crucial step in the identification of novel drugs which can be considered for clinical application (Saurav \& Kannabiran, 2011). The potentia of Streptomyces sp. for the production of bioactive compounds were discovered decades before. But the strain specific biosynthetic variations and endophyte specific biosynthetic potential acquired by them is least studied. This highlights the importance of screening actinomycetes present in a metabolite rich plant like Piper nigrum.

\section{CONCLUSION}

In the current study three endophytic actinomycetes were isolated from the stem region of Piper nigrum. All the three isolates were found to have antibacterial, antioxidant and anticancer activity. However the isolate PnA 1 identified as Verrucosispora sp was found to have higher anticancer and antimicrobial activity and PnA 2 identified as Streptomyces sp. showed excellent antioxidant activity. The obtained results are supported by many reports as several bioactive metabolites have been identified from related isolates.

Acknowledgement: This study was supported financially by Department of Biotechnology (DBT), Government of India under DBT-RGYI support scheme.

Conflict of interest statement: We declare that we have no conflict of interest.

\section{REFERENCES}

ALlAMEH, A., SAXENA, M., BISWAS, G., RAJ, H. G, SINGH, J., SRIVASTAVA, N. 1992. Piperine, a plant alkaloid of the piper species, enhances the bioavailability of aflatoxin B1 in rat tissues. Cancer Lett. 61, 195-199, http://dx.doi.org/10.1016/0304-3835(92)90287-6

CASTILLO, U.F., BROWNE, L., STROBEL, G.A., HESS, W.M., EZRA, S., PACHECO, G., EZRA, D. 2007. Biologically active endophytic Streptomycetes from Nothofagus spp. and other plants in Patagonia. Microb Ecol, 53, 12-19, http://dx.doi.org/10.1007/s00248-006-9129-6

CHANG, H.B., KIM, J. 2007. Antioxidant properties of dihydroherbimycin A from a newly isolated Streptomyces sp. Biotechnol. Lett, 29, 599-603, http://dx.doi.org/10.1007/s10529-006-9288-Z

CLARRIDGE, J.E. 2004. Impact of $16 \mathrm{~S}$ rRNA gene sequence analysis for identification of bacteria on clinical microbiology and infectious diseases. Clin. Microbiol. Rev, 17, 840-862, http://dx.doi.org/10.1128/CMR.17.4.840-862.2004 COOMBS, J.T., FRANCO, C.M.M. 2003. Isolation and identification of actinobacteria from surface-sterilized wheat roots. Applied Environ. Microbiol. 69, 5603-5608, http://dx.doi.org/10.1128/AEM.69.9.5603-5608.2003

FIEDLER, H.P., BRUNTNER C, RIEDLINGER, J., BULL, A.T., KNUTSEN, G., GOODFELLOW, M., JONES, A., MALDONADO, L., PATHOM-AREE W., BEIL, W., SCHNEIDER, K., KELLER, S., SUSSMUTH, R.D. 2008 Proximicin A, B and C, novel aminofuran antibiotic and anticancer compounds isolated from marine strains of the actinomycete Verrucosispora. J Antibiot, 61, 158-163, http://dx.doi.org/10.1038/ja.2008.125

GHADIN, N., ZIN, N.M., SABARATNAM, V., BADYA, N., BASRI, D.F. LIAN, H.H., SIDIK, N.M. 2008. Isolation and characterization of a novel endophytic Streptomyces SUK 06 with antimicrobial activity from Malaysian plant. Asian J. Plant Sci. 7, 189-194, http://dx.doi.org/10.3923/ajps.2008.189.194. HE, F., YANG, Y., YANG, G., YU, L. 2008. Components and Antioxidant Activity of the Polysaccharide from Streptomyces virginia H03. Zeitschrift fur $\begin{array}{llll}\text { Naturforschung } & C \text {-J. Biosci, } & 63, & 181-188,\end{array}$ http://dx.doi.org/10.1016/j.ijbiomac.2011.05.028.

HOSOYA, Y., ADACHI, H., NAKAMURA, H, NISHIMURA, Y., NAGANAWA, H., OKAMI, Y., TAKEUCHI, T. 1996. The structure of diphenazithionin, a novel antioxidant from Streptomyces griseus ISP 5236 Tetrahedron Lett, 37, 9227-9228, http://dx.doi.org/10.1016/S00404039(96)02190-9.

HOUBO, WU., WEN, CHEN., GUANGHUA, WANG., SHIKUN, DAI. DANYAN, ZHOU., HENGZHI, ZHAO., YATAO, GUO., YONGCHANG, OUYANG., XIANG, LI. 2012. Culture-dependent diversity of Actinobacteria associated with seagrass (Thalassia hemprichii). Afr J Microbiol Res, 6, 87-94, http://dx.doi.org/10.5897/AJMR11.981.

JASIM, B., JIMTHA, JOSEPH., JYOTHIS, MATHEW., RADHAKRISHNAN, E.K. 2013. Plant growth promoting potential of endophytic bacteria isolated from Piper nigrum. Plant Growth Regul, 71, 1-11, http://dx.doi.org/10.1007/s10725013-9802-y

KAWADA, T., SAKABE, S. 1988. Some pungent principles of spices cause the adrenal medulla to secrete catecholamines in anesthetized rats. Proc Soc Exp Biol Med. 188:229-233, http://dx.doi.org/10.3181/00379727-188-2-RC1.

KHAJURIA, A., THUSU, N., ZUTSHI, U. 2002. Piperine modulates permeability characteristics of intestine by inducing alterations in membrane dynamics: influence on brush border membrane fluidity, ultrastructure and enzyme kinetics. Phytomedicine. 9, 224-231, http://dx.doi.org/10.1078/09447113-00114

KIM, K.J., KIM, M.A., JUNG, J.H. 2008. Antitumor and antioxidant activity of protocatechualdehyde produced from Streptomyces lincolnensis M-20. Arch Pharmacal. Res, 31, 1572-1577, http://dx.doi.org/10.1007/s12272-001-2153-7. KOMIYAMA, K., FUNAYAMA, S., ANRAKU, Y., MITA, A., TAKAHASHI, Y., OMURA, S., SHIMASAKI, H. 1989. Isolation of isoflavonoids possessing antioxidant activity from the fermentation broth of Streptomyces sp. J. Antibiotics, 42, 1344-1349, http://dx.doi.org/10.7164/antibiotics.42.1344.

Lee, E.B., Shin, K.H., Woo, W.S. 1984. Pharmacological study on piperine. Arch Pharmacol Res. 7, 127-132, http://dx.doi.org/10.1007/BF02856625.

LOCCI, R. 1989. Streptomyces and Related Genera. In: Bergeys Manual of Systematic Bacteriology, Williams, S.T., M.E. Sharpe and J.G. Holt (Eds.) Willians and Wilkins. Baltimore. 2452-2492.

LONG, H.H., SCHMIDT, D.D., BALDWIN, I.T. 2008. Native Bacterial Endophytes Promote Host Growth in a Species-Specific Manner; Phytohormone Manipulations Do Not Result in Common Growth Responses. PLoS ONE, 3 , 2702, http://dx.doi.org/10.1371/journal.pone.0002702.

MOSMANN, T. 1983. Rapid colorimetric assay for cellular growth and survival: application to proliferation and Cytotoxicity assays. J. Immunol. Methods, 65, 55, http://dx.doi.org/10.1016/0022-1759(83)90303-4.

QIN, J.C., ZHANG, Y.M., GAO, J.M., BAI, M.S., YANG, S.X., LAATSCH, H., ZHANG, A.L. 2009. Bioactive metabolites produced by Chaetomium globosum an endophytic fungus isolated from Ginkgo biloba. Bioorganic Med. Chem. Lett, 19, 1572-1574, http://dx.doi.org/10.1016/j.bmcl.2009.02.025.

RIEDLINGER, J., REICKE, A., ZA"HNER, H., KRISMER, B., BULL, A.T., MALDONADO, L.A., WARD, A.C., GOODFELLOW, M., BISTER, B., BISCHOFF, D., SÜSSMUTH, R.D., FIEDLER, H.P. 2004. Abyssomicins, inhibitors of the para-aminobenzoic acid pathway produced by the marine Verrucosispora strain AB-18-032. J. Antibiot, 57, 271-279, http://dx.doi.org/10.1038/ja.2007.54.

RIHUA, XU., NAN, SHANG., PINGLAN, LI. 2011. In vitro and in vivo antioxidant activity of exopolysaccharide fractions from Bifidobacterium animalis RH. Anaerobe, 17, 226-231, http://dx.doi.org/10.1016/j.anaerobe.2011.07.010.

ROH, H., UGURU, G.C., KO, H.J., KIM, S., KIM, B.Y., GOODFELLOW, M. BULL, A.T., KIM, K.H., BIBB, M.J., CHOI, I.G., STACH, J.E.M. 2011. Genome sequence of the abyssomicin- and proximicin producing marine actinomycete Verrucosispora maris AB- 18-032. J. Bacteriol, 193, 3391-3392 http://dx.doi.org/10.1128/JB.05041-11.

SAURAV, K., KANNABIRAN, K., 2011. Biosorption of Cr (III) and Cr (VI) by Streptomyces VITSVK9 sp. Ann Microbiol, 61, 833-841, http://dx.doi.org/10.1007/s13213-011-0204-y.

SHIRAI, M., OKUDA, M., MOTOHASHI, K., INOTO, M., FURIHATA, K., MATSUO, Y., SHIZURI, Y., SETO, H. 2010. Terpenoids produced by actinomycetes: isolation, structural elucidation and biosynthesis of new diterpenes: gifhornenolones A and B from Verrucosispora gifhornensis YM28088. J Antibiot, 63, 245-250, http://dx.doi.org/10.1038/ja.2010.30.

SILAMBARASAN, S., PRAVEEN KUMAR, E., MURUGAN, T., SARAVANAN, D., BALAGURUNATHAN, R. 2012. Antibacterial and antifungal activities of Actinobacteria isolated from Rathnagiri hills. Journal of Applied Pharmaceutical Science, 2, 099-103, http://dx.doi.org/10.7324/JAPS.2012.21020.

TAECHOWISAN, T., LU, C., SHEN, Y., LUMYONG, S. 2005. Antitumor activity of 4-Arylcoumarins from endophytic Streptomyces aureofaciens CMUAc130 and their antifungal activity. Ann Microbiol, 55, 63-66, http://dx.doi.org/10.4103/0973-1482.34685.

TAMURA, K., PETERSON, D., PETERSON, N., STECHER, G., NEI, M., KUMAR, S. 2011. MEGA5: Molecular Evolutionary Genetics Analysis using Maximum Likelihood, Evolutionary Distance, and Maximum Parsimony $\begin{array}{lllll}\text { Methods. } & \text { Mol Biol 2731-2739, }\end{array}$ http://dx.doi.org/10.1093/molbev/msr121

THENMOZHI, M., KANNABIRAN, K. 2012. Antimicrobial and antioxidant properties of marine actinomycetes Streptomyces sp. VITSTK7. Oxid Antioxid Med Sci, 1, 51-57, http://dx.doi.org/10.5455/oams.270412.or.005.

TRIPATHI, P., TRIPATHI, G.S. 1989. Thyrogenic response of Piper nigrum Fitoterapia. 60, 539-542, http://dx.doi.org/.

VIJAYAKUMAR, R.S., SURYA ,D., NALINI, N. 2004. Antioxidant efficacy of black pepper (Piper nigrum L.) and piperine in rats with high fat diet induced $\begin{array}{llll}\text { oxidative stress. Redox } & \text { Rep, } & \text { 9, } & \text { 105-110, }\end{array}$ http://dx.doi.org/10.1179/135100004225004742.

VLADIMIROV, YU., PARFENOV, E., EPANCHINTSEVA, O., SMIRNOV, L.D. 1991. Antiradical activity of coumarin reductones. Byul Eksperimen Biol Med, 112, 475-478.

ZHANG, Z., SCHWARTZ, S., WAGNER, L., MILLER, W. 2000. A greedy algorithm for aligning DNA sequences. J Comput Biol, 7, 203-214, http://dx.doi.org/10.1089/10665270050081478.

ZIN, N.M., NG, K.T., SARMIN, N.M., GETHA, K., TAN, G.Y. 2011. Antitrypanosomal Activity of Endophytic Streptomycete. Current Research in Bacteriology, 4, 1-8, http://dx.doi.org/10.3923/crb.2011.1.8. 